\title{
Erratum to: Antioxidant Properties of Extracts Obtained from Raw, Dry-roasted, and Oil-roasted US Peanuts of Commercial Importance
}

\author{
Brian David Craft • Agnieszka Kosińska • \\ Ryszard Amarowicz • Ronald Bruce Pegg
}

Published online: 2 July 2010

(C) Springer Science+Business Media, LLC 2010

\section{Erratum to: Plant Foods for Human Nutrition \\ DOI: $10.1007 / \mathbf{s} 11130-010-0160-x$}

The following errors were found in this paper:

1. This particular paragraph in the Results and Discussion section is incorrect:

The most significant increase in free p-coumaric levels was found in a high-oleic Runner (S \#8): an increase of 393 and absorbances \& $785 \%$ for the dry and oil-roasted sample, respectively, was calculated.

This should be:

The most significant increase in free p- coumaric levels was found in a high-oleic Runner (S \#8): an increase of 393 \& 785\% for the dry- and oil-roasted sample, respectively, was calculated.

2. There are incorrect data in Table 1 . The correct one is on the next page:

The online version of the original article can be found under http://dx. doi.org10.1007/s11130-010-0160-x.

B. D. Craft $\cdot$ R. B. Pegg $(\bowtie)$

Department of Food Science and Technology,

The University of Georgia,

100 Cedar Street,

Athens, GA 30602-7610, USA

e-mail: rpegg@uga.edu

\section{A. Kosińska • R. Amarowicz}

Division of Food Science, Institute of Animal Reproduction

and Food Research of the Polish Academy of Sciences,

ul. Tuwima 10 ,

10-747 Olsztyn, Poland

Present Address:

B. D. Craft

Department of Food Science \& Technology,

Nestlé Research Center,

Vers-chez-les-blanc, Case Postale 44,

1000 Lausanne 26, Switzerland 


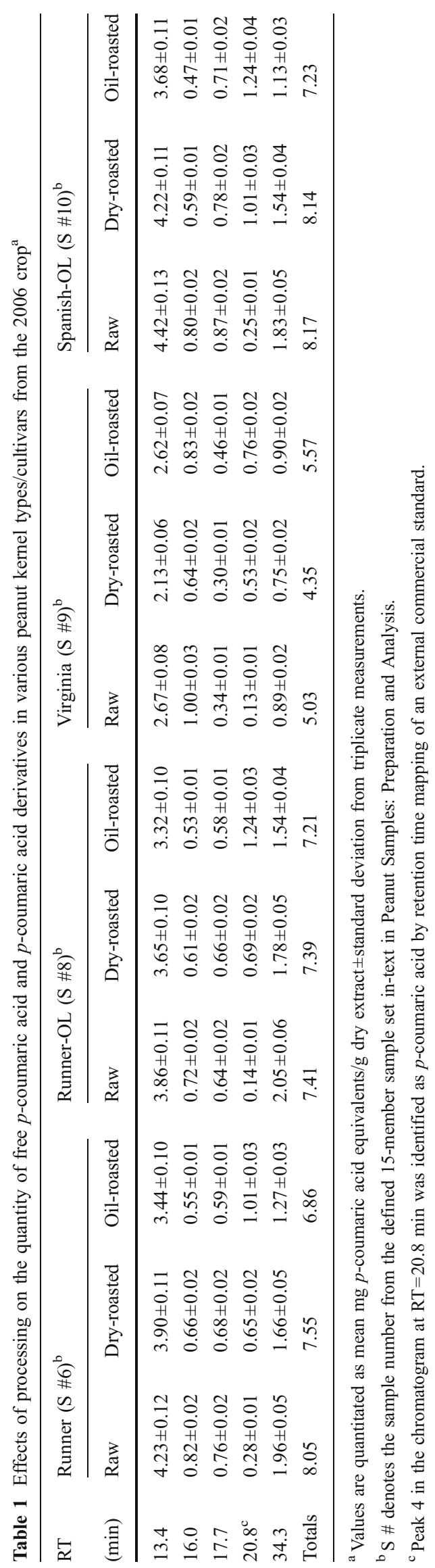

